\title{
CLAVES PLÁSTICAS Y EXPRESIVAS DE LA NOCHE OSCURA
}

VIRGINIA SANTOS-RIVERO

Yale University

\section{RESUMEN}

Se analizan los diversos elementos estéticos que conforman la poesía Noche oscura del alma de Juan de la Cruz, para poder dilucidar las claves estéticas del poema que marcan sus relaciones internas, y la manera en que se complementan o se resaltan recíprocamente.

En el periodo histórico en el que vive Juan de la Cruz, el monje carmelitano, se produce un fenómeno en toda la península en virtud del cual «el alma española va a volverse hacia dentro; su cultura entra en un proceso de involución»'. Una de las manifestaciones más características que esta tendencia genera es la peculiar literatura mística española, la cual, al tratar de expresar o describir «el conocimiento experimental de la presencia divina que el alma tiene, como una gran realidad, un sentimiento de contacto con Dios» ${ }^{2}$, forjará un

1 SAINZ DEL Río, citado por Alborg, Historia de la Literatura española (Madrid: Gredos, 1967) I 867.

${ }^{2}$ HaRTfeld, Estudios literarios sobre mística española. Citado por Alborg 876. 
nuevo lenguaje, tanto en prosa como en verso, renovando profundamente las formas de expresión con fórmulas y recursos hasta entonces no utilizados, y con logros estilísticos nunca después equiparados.

Dámaso Alonso en su obra La poesía de San Juan de la Cruz, estudió la cuestión de las fuentes que convergen en el poeta, agrupándolas en tres tipos: italianizantes, de tipo tradicional, y bíblicas. En esta obra, Alonso demostró cómo la originalidad de San Juan no proviene de la utilización de nuevos símbolos, imágenes poco usuales o un innovador lenguaje poético, ya que en la mayoría de las ocasiones, sigue al fiel refundidor «a lo divino» de Garcilaso, Sebastián de Córdoba, cuando no bebe directamente del texto bíblico, o refunde el mismo canciones de tipo tradicional. Su originalidad radica precisamente en la nueva dimensión que dio a ese mismo lenguaje, y a la simbología que creó para tratar de expresar lo inexpresable, para intentar decir lo indecible: éste constituye el problema de la mística por excelencia, el encontrar un método y un medio de expresión adecuados a las experiencias que están más allá del lenguaje y de la representación.

Con estos fines y según Antonio Prieto, «los místicos españoles buscaron una lengua alógica que pudiera expresar en la vivencia de las metáforas lo que su estado precisaba, y entendieron la metáfora como una potenciadora del lenguaje emotivo y crearon una lengua, apoyada en una sintaxis de oraciones subordinadas, de una fuerza extraordinaria.» ${ }^{3}$ Esta renovación de la lengua obedece por lo tanto a la necesidad de la mística de expresar lo inefable, y que, consecuentemente, discurre por recorridos de intensa connotación.

En este sentido, Juan de la Cruz intento expresar algo que, por definición, estaba fuera de la realidad. Este fuerte valor connotativo, la convierte en una lengua esencialmente poética y lírica, que alcanza sus más altas cotas con Juan de la Cruz. Y esto nos lleva a un doble plano de significado en la codificación de las palabras y, por extensión, de las imágenes poéticas que utiliza. El mismo significante adquiere bien un significado objetivo, religioso, o afectivo, o bien un significado de profunda simbología cósmica, como es el caso de la palabra "noche», en la que este desdoblamiento adquiere dimensiones extremas. Desde un punto de vista meramente cotidiano, la mística tenia que acudir, como nos dice Prieto, para expresar su inefable extrarrealidad a un lenguaje connotativo ${ }^{4}$. Y de ahí una de las causas que determinan esta poesía que se escribe a posteriori para expresar una fuerte experiencia religiosa, psicológica y

${ }^{3}$ ANTONio PRIETo, Introducción a Luz y oscuridad en la mística española, por María Jesús Fernández de Leborans (Madrid: Cupsa, 1978) 14.

${ }^{4}$ Prieto, 16. 
humana, cuya esencia no había sido descrita hasta entonces con la plenitud poética que logró Juan de la Cruz: el ímpetu de la experiencia se corresponde con la intensidad de la fuerza creativa de su lenguaje poético.

De hecho, y a diferencia de Santa Teresa, la poesía de San Juan será plenamente comprendida sólo por los que participan de su código místico, y será incomprensible para un receptor ajeno a sus vivencias, lo cual no obsta para que no sea comunicable desde un plano afectivo.

En el poema de la Noche específicamente, el poeta canta la huida del alma, en medio de la noche, de la prisión de los sentidos, y al fin, libre de ellos, la unión con el amado ${ }^{5}$. Como en sus otro dos poemas místicos, hay un dialogo dirigido a su propia alma, que es, en cierto modo, una forma de dirigirse a Dios. Esto está de acuerdo con la teoría platónica renacentista según la cual, el alma humana es lo que más se aproxima a la divinidad en el hombre, ya que es no solo reflejo de Dios, sino que dimana de Él; por lo tanto es en el alma en donde se encuentra, en donde mora Dios. Este es el origen del movimiento de introspección de los místicos españoles. Este mirar hacia sí, hacia dentro, crea un movimiento que será, en un momento inicial, de introspección, y después de descubrir la luz de Dios, será un movimiento ascensional para alcanzar la unión mística con Dios.

En un principio, pues, se realiza un acto de comunicación hacia sí mismo, que requiere el previo salirse de sí, para, a continuación, volverse hacia sí, hacia el alma donde está Dios, y finalmente elevarse hacia Él, con un reafirmarse en sí mismo en lo que se atañe a la parte que el alma comparte con Dios, y un desprenderse de sí mismo en lo que se refiere a los sentidos y a los apetitos carnales.

En cuanto a los elementos estilísticos de la Noche, y dejando a un lado la polémica de la preocupación estética o no de su autor, lo primero que nos llama la atención en este poema de ocho estrofas es que, estando escrito en liras, la acentuación de los versos caiga (excepción hecha del verso 15) en la sílaba sexta de cada verso. Ello produce una reiteración que podría calificarse de incisiva, o que pudiera ser interpretada como prueba fehaciente de que el autor no dominaba plenamente la técnica musical de esta recién introducida, aunque ya plenamente adoptada, estrofa, la lira. Otros autores, como Gracilazo de la Vega y Fray Luis de León, que si bien no fueron estrictamente coetáneos de Juan de la Cruz, sí pertenecieron al mismo periodo renacentista, acentuaron sus liras en las sílabas cuarta y octava. Sin embargo, y de acuerdo con Dámaso Alonso, Juan de la Cruz no aparece por esto ajeno a los problemas técnicos de

\footnotetext{
5 ALBORG, 910.
} 
la forma poética, sino que al ser sinalefado, y con «única acentuación en sexta le da mayor rapidez, porque la rítmica imaginativa no necesita transponer más que una cumbre»" 6 .

El análisis de la rima, en consonante, nos ofrece el siguiente esquema en cada una de las estrofas:

$\begin{array}{lllll}\text { a } & B & a & b & B \\ \text { a } & B & a & b & B \\ \text { c } & D & c & d & D \\ \text { e } & D & e & d & D \\ \text { f } & B & f & b & B \\ \text { g } & E & g & e & E \\ \text { h } & D & h & d & D \\ i & J & i & j & J,\end{array}$

de cuyo estudio podemos extraer varias conclusiones. Las dos primeras estrofas, que junto con la tercera forman una unidad conceptual, tienen idéntica rima, en $a$ y $b$, lo cual nos mantiene en la misma escena, al evocar los ritmos el mismo sonido. En la tercera, introduce las rimas $c$ y $d$, con un cambio brusco de la cadencia acústica, donde acaba de describir el estado en que «salió». Desde este momento poético, nos introduce en la cuarta estrofa, en la que explica quién la esperaba, impulsando nuestro pensamiento hacia adelante, con una fuerza direccional «a donde», y al mismo tiempo, enlazando con la estrofa anterior, pues es la misma luz "que en el corazón ardía» la que le guiaba; así introduce en el primer verso la rima e y la combina con la ya utilizada $d$. En la quinta estrofa, el poeta rompe en una exclamación de júbilo, un alto en el camino para dar un respiro a la intensa emoción; introduce una nueva rima, $f$, pero la mezcla con otra anteriormente utilizada en las dos primeras estrofas, la $b$, creando una moción circular que da continuidad a la pasión expresada desde la primera estrofa.

Las tres últimas estrofas, sexta séptima y octava, tratan de la unión mística propiamente dicha, constituyendo así el clímax del poema, y el punto álgido de la tensión dramática de lo que está siendo relatado. En la sexta y séptima estrofas, cuando relata algunos de los efectos de esta unión, combina en ambas estrofas respectivamente, una rima nueva, $f$ y $g$, con una ya utilizada, $b$ y $e$. Y al llegar a la culminación del proceso, ya en la última estrofa, introduce dos rimas completamente nuevas para resaltar la pérdida de toda referencia a

6 Dámaso Alonso, La poesía de San Juan de la Cruz (Madrid: Aguilar, 1966) 136-138. 
la realidad o a lo anteriormente vivido, como efecto de dejar su «cuidado entre las azucenas olvidado».

La utilización de los verbos en el poema es así mismo reveladora. Como ha notado Dámaso Alonso, hay en este poeta lo que él llama una escasez del verbo ${ }^{7}$. Si bien, aunque escaso, la localización de los verbos a lo largo del poema obedece a una función expresiva.

Uno de los rasgos más llamativos del poema en cuanto a su estructura, es el que en las tres primeras estrofas, la única acción verbal nos viene dada por el verbo «salí», ubicado en la primera estrofa, al que corresponden y se supeditan los complementos múltiples que conforman dichas tres estrofas. Este primer verbo nos revela cómo ocurrió la acción en un momento temporal del pasado, y con la certeza del acontecimiento experimentado, todo lo cual nos viene dado por la utilización del pretérito perfecto de indicativo. Y el otro dato fundamental que este verbo nos aporta es que la narración se produce en primera persona. Después de dos estrofas sin verbo, la cuarta, que es la más dinámica, introduce cuatro verbos en pretérito imperfecto de indicativo, que nos siguen describiendo una acción ocurrida, «real», pero que estiran el tiempo verbal cubriendo todo el acontecimiento, y dándole una duración que, al no especificar su principio (¿desde cuándo le «guiaba»?; por supuesto que le guiaba desde que salió hasta que, en la estrofa siguiente, se juntó el amado con la amada, pero también, una característica inmanente - aunque en potenciaa la «luz que en el corazón ardía» es la de guiar, por lo tanto esta acción de guiar sobrepasa en el tiempo a la acción narrada), le presta un matiz, si no de eternidad, sí de una mayor duración temporal. Y, de una forma análoga, «esperaba» se alarga en duración, pues Dios no «comienza» o «termina» una acción, sino que la contiene total y eternamente. «Sabía» alude al conocimiento que el asceta ejercitado, y sobre todo, el que ha tenido experiencias místicas, tiene de Dios, ya que ha mirado dentro de su alma para encontrarlo, y de hecho lo ha encontrado, por eso «bien lo sabía». Por otra parte, «... donde nadie parecía» describe la soledad e individualidad de la experiencia mística. El hecho ocurre en presencia de nadie, ello nos da una idea del sentimiento humano al enfrentar su espíritu desnudo ante la grandeza cósmica; es la negación o ausencia de otros seres, ya que se trata de la unión íntima del alma con Dios, punto en el cual «nadie parecía» ni antes ni después de la consumación, subraya así el carácter unívoco y profundamente lírico de esta unión. Y no da lugar a ninguna interpretación que vaya más allá de lo estrictamente personal e intransferible. 
En la quinta estrofa, que es una honda y espontánea exclamación a la noche, no hay un verbo principal, y con los dos verbos de sendas oraciones subordinadas de relativo, ambos en pretérito indefinido, se sale del tiempo de la narración para contemplar a cierta distancia lo que hubo ocurrido, que al moverse al momento actual de la narración y situarse en el presente, toda la experiencia de que trata ya ha terminado - aunque no sus reminiscencias-; supone pues un salto no sólo en el tiempo, sino también dentro de su alma en el estado anímico, punto desde donde el narrador es capaz de una valoración de los efectos que la noche le produjo. «Guiaste» $y$ «juntaste» son las proezas maravillosas que realizó la noche, y que aun después de haber pasado, todavía producen un escalofrió en el recuerdo del poeta.

A partir de la sexta estrofa, la unión con Dios se hace más difícil de describir; es así como en la sexta estrofa, y quizás debido al anonadamiento producido por el encuentro, y por única vez en todo el poema, se mezclan los tiempos verbales, el pretérito imperfecto de indicativo y el indefinido, expresando con ello la dificultad de localizar en unas coordenadas temporales ese salirse del mundo sensible.

La siguiente estrofa, la séptima, nos vuelve a centrar sobre el hecho de la unión, cuyo tiempo se alarga, esta vez saboreando con deleite los efectos de la misma, pero de una manera simultanea y coherente, pues los tres verbos (todos ellos en pretérito imperfecto de indicativo) describen acciones coetáneas que quedan sincronizadas por el adverbio «cuando». En la última estrofa, asistimos a una sucesión continua de cinco verbos, con acciones que se suceden una a otra repetitivamente, y que no revelan acción y movimiento como cabría esperar de tal cúmulo de verbos, sino que, en una moción acelerada, despojan sucesiva y rítmicamente al protagonista de todo dinamismo, y de los vínculos sensoriales que le unen a la Tierra y a su conciencia de ser humano. Al mismo tiempo, el gerundio «dejando», en acción concomitante y como contrapunto, describe el estado al que va acercándose inexorablemente, para acabar de la forma más lírica posible, «entre las azucenas olvidado».

La utilización de los tiempos verbales, es la base sobre la que se asienta el ritmo del poema: «lo importante es dejarse llevar por la urgencia del poema cuando fluye rápidamente hacia su apogeo. La repetición y el eco de ciertas palabras y frases aumenta el sentido de urgencia...(en) una cadena de palabras que nos lleva adelante con rapidez hacia el clímax..." ${ }^{8}$ con la urgencia del proceso místico para alcanzar, finalmente, un reposo de dimensiones cósmicas y universales.

${ }^{8}$ RoYston OSCAR JONEs, Historia de la literatura española, (Barcelona: Ariel, 1972) 171. 
El cambio del sujeto verbal también expresa el cambio de la acción y nos lleva de la primera persona en las tres primeras estrofas. La voz en primera persona es la que experimenta y narra la acción, a la tercera persona de la cuarta estrofa, aunque quien sigue recibiendo el beneficio de esta acción del verso 16 , así como del verso 18 , es la primera persona, mientras que en el verso 19, el verbo, de nuevo en primera persona, subraya y personaliza la acción al hacerse reflexivo, mientras que «parecía» del verso 20 , introduce un esbozo de ambientación, de escena de fondo - si bien emotiva - saliéndose de la absorbente vivencia del amado y la amada. Aprovechando esta pausa entre los amantes, la apelación en segunda persona a la noche sirve de punto de inflexión en la construcción del poema, ya que a partir de aquí pasará a cantar la parte mística propiamente dicha.

A continuación se inicia un juego de acciones recíprocas entre el amado, la amada y el aire, para, en la estrofa final, reiterativamente volverse a la primera persona, con la excepción de «cesó todo», el telón de fondo sobre el que resaltan la consumación de las acciones de abandono restantes, las cuales, al coincidir en persona y tiempo con el primer verbo del poema en la primera estrofa, enlazan con ésta, dando unidad temporal a la obra dentro de la diversidad transitoria.

Alonso señala la función predominante del sustantivo a expensas de la función verbal; en toda la poesía de Juan de la Cruz, lo cual da como resultado una gran condensación de materia ${ }^{9}$. En un estudio más detallado de la distribución de sustantivos y verbos en la Noche, nos da como resultado el siguiente esquema:

\begin{tabular}{lllllllll}
\hline estrofas & 1 & 2 & 3 & 4 & 5 & 6 & 7 & 8 \\
sustantivos & 5 & 4 & 5 & 3 & 8 & 4 & 6 & 4 \\
verbos & 1 & - & - & 4 & - & 3 & 3 & 5 \\
\hline
\end{tabular}

$\mathrm{Si}$, como dice Lamiquiz, en la sistematización de la lengua se manifiestan el espacio y el tiempo, apareciendo en el aspecto sintáctico el sustantivo como categoría que manifiesta los valores espaciales, y el verbo como categoría que expresa los valores temporales ${ }^{10}$, podríamos interpretar el poema de la Noche en el sentido de que en tres de sus estrofas no existe sino un solo verbo principal, siendo una de ellas, la quinta, en contrapartida, la que tiene más sustantivos: ocho en total.

9 DÁmaso Alonso 136-138.

10 Vidal. LamiQuiz, El sistema verbal del español (Málaga: Ágora, 1982) 19-20. 
En la totalidad del poema, y en un intento de matematizar este aspecto del poema -quizás como recuerdo a Pitágoras, la relación sustantivo-verbo es aproximadamente de 3 a 1, lo cual nos lleva a la conclusión de que para expresar su experiencia, el santo carmelitano lo hace a través de categorías espaciales, que pueden adaptarse mejor al concepto de la negación del «yo» y el salirse de sí (que más tarde analizaremos), siendo el tiempo cronológico menos enfatizado. Este rasgo se puede atribuir a la riqueza de matices que puede expresar los tiempos verbales en castellano, posibilidad que ofrece la lengua al poeta y que este utiliza con consumado sentido artístico y expresivo.

En cuanto a la estructura del poema, observamos que, siguiendo una cierta simetría en la ordenación de sus dos mitades, encontramos que en la cuarta y la octava estrofas la proporción sustantivo-verbo se invierte, lo cual hace resaltar más y por contraste el fenómeno arriba estudiado de la especialidad. La escasez del epíteto ha sido subrayada asimismo por Dámaso Alonso: si como el crítico explica, el epíteto o adjetivo analíticos extrae del sustantivo una cualidad inherente a él "1, en todo el poema de la Noche no encontramos sino tres epítetos en total, en las dos primeras estrofas, versos 3 («dichosa ventura»), 7 («secreta escala»), y 8 («dichosa ventura» de nuevo), lo cual nos dice que la cualidad coesencial del recorrido místico es su índole personal e intransferible, además de intimista e individual, y por supuesto, no hace falta señalar, que la satisfacción que produce no es pena, sino ventura en el mismo sentido en el que usa la palabra Cervantes como recoge Ruano ${ }^{12}$, y no ventura sin mas, sino ventura dichosa.

Entre los recursos retóricos que utiliza, destaca la aliteración de los últimos versos de las dos primeras estrofas respectivamente, «estando ya mi casa sosegada», que marca la pauta del estado anímico de sosiego y tranquilidad que el alma había alcanzado antes de emprender la ascensión. En la estrofa quinta hace uso de la anáfora, que, además supone un paralelismo sintáctico que recalca el punto de encuentro desde el cual y seguidamente, sin solución de continuidad, se realizará la unión.

En torno a la temática del poema, nos hemos de referir a Dámaso Alonso una vez más, quien apunta que «La base de la poesía de San Juan de la Cruz, de la mayor parte de su poesía, es la alegoría simbólica» ${ }^{13}$. Dentro de la simbología que creó Juan de la Cruz, es el símbolo de la noche - la mayoría de los críticos coinciden en señalarlo, aunque no coincidan tanto en la interpreta-

1 AlONSO, 143.

12 Argimiro Ruano, San Juan de la Cruz clásico. Teoría de lo inefable (Río Piedras: Edil, 1971) 69

13 AlONSO, 149. 
ción que le dan- es su máxima creación poética, cuyo significado analizaremos con más detalle a continuación.

La imagen de la noche, como otras que Juan de la Cruz utiliza, no es originalmente creación suya; ya la encontramos en poetas de tradición cristiana culta como Garcilaso, así como en poetas musulmanes como Ibn Abbad de Ronda, Niffari, y Lahiyi ${ }^{14}$.

En una somera mirada sobre las diversas interpretaciones que han sido dadas al sentido que Juan de la Cruz dio al símbolo de la noche, que creemos necesario dado el carácter polémico de esta interpretación, podemos citar a Eulogio Pacho: «Nos escapa la relación... entre el sentido simbólico de los términos poéticos y el sentido real que tienen las mismas palabras... El nexo lo puede establecer solamente quien tiene la clave de la intencionalidad de su terminología figurada: el autor mismo» ${ }^{15}$. Sin embargo, para Jean Baruzi, «nous entrevoyons une contemplation naturelle extatique... transformée en un sorte d'absolu» ${ }^{16}$ [se entrevé una contemplación natural, extática... transformada en una especie de absolutol, visión con cuyos aspectos estático y absoluto estamos enteramente de acuerdo, como ha sido corroborado anteriormente en nuestro análisis estilístico del poema.

Quien profundiza en el significado de «noche» y lo analiza y estudia de forma más completa es María Jesús Fernández de Leborans, que al estudiar la obra de San Juan de la Cruz, parte de la base de que en ella « no existe denotación, especialmente en las composiciones poéticas» ${ }^{17}$. Sus posteriores explicaciones vienen a enlazar con la visión cósmica de Baruzi: «La noche, imagen arquetípica significante de concepciones metafísicas o teológicas en las antiguas cosmogonías y teogonías, y símbolo, también arquetípico, de ideologías místico-religiosas, es, en San Juan de la cruz, la imagen de una singular cosmovisión»" ${ }^{18}$

El sentido que este símbolo desarrolla y alcanza con San Juan, concuerda con las teorías neoplatónicas del amor, que fueron cultivadas con entusiasmo y fruición por los filósofos musulmanes españoles, como Abenarabí de Murcia: «lo amado no es el amado, pues lo que el amante busca y apetece no es la per-

14 LUCE LOPEZ-BARAlt, Huellas del Islam en la Literatura española. De Juan Ruiz a Goytisolo (Madrid: Hiperión. 1985) 10.

"Eulugio PaCHo, Vértice de la poesía y de la mística. El Cántico espiritual de San Juan de la Cruz (Burgos: Monte Carmelo, 1983) 10.

is Jfan BARUzi, Saint Jean de la Croix et le problème de l'expérience mystique (Paris: AlCan, 1924) 231 .

17 Fernández. de leborans, 154.

18 Fernández de Leborans. 158. 
sona misma a quien ama, sino algo de esta que para el amante no existe todavía, es decir, su vista, su trato y conversación, besarla o abrazarla y unirse con ella. Logrado eso que ama, el amante sigue todavía amando su continuidad o reiteración, que tampoco existe aún. Luego el objeto del amor es siempre algo que no existe» ${ }^{14}$.

Otro rasgo platonizante de la búsqueda del amado, es que lo que anhela el alma del místico, que es la unión con Dios, sólo puede ser realizado desde la negación de lo que de humano o no-divino tiene el alma, es decir; desde el despojamiento de lo desememjante de Dios, ya que únicamente se puede realizar la unión de lo que es semejante, lo que infunde el profundo dramatismo que, como experiencia humana supone el negarse así mismo y negarse su condición de hombre, de persona y de criatura, de ser creado por Dios. Esto implica que el objetivo deseado, la unión, es por definición un estado del alma inexistente, y que el místico buscará con desazón para lograr su objetivo.

Es pues la noche de los sentidos, de los lazos terrenales, como nos dice la exégesis religiosa, pero es también en un sentido que podríamos calificar de trágico, la negación total de su yo humano. Según Leborans, «el intenso drama espiritual se realiza sin regresiones, proyectándose de forma progresiva hacia la desnudez y renuncia absolutas hasta alcanzar la unión transformadora en el amado» ${ }^{20}$.

Tiene que negarse a sí mismo, su naturaleza y su esencia. La noche y su simbología se convierten así en la esencia misma, la condición previa y sine qua non para alcanzar la inteligencia mística de Dios, para llegar al total conocimiento de Dios por medio del amor. Sin embargo, y a pesar de este dramatismo, y debido a los efectos que produce y el objetivo que se alcanza, la noche es una noche amable, es una noche que, en figura prosopopéyica, hace posible la unión, no solo del amado con la amada, sino de la amada transformada en el amado-Dios, despojada de todo su bagaje temporal-sensitivo-humano; es una noche que merece la exclamación jubilosa y encomiante, y a la que se está agradecido. En palabras de Rollán, el proceso es descrito como sigue: «Así el vaciamiento o despojamiento del yo, no sería aniquilación ontológica, es decir, destrucción del ser personal, sino acceso al ser que, en el colmo del vaciamiento, del despojo, de la privación, se descubría doblemente enriquecido" ${ }^{21}$.

1" Micilet Asin Palacios. El Islam cristianizado. Estudio del sufismo a través de las ohras de Abenarabi de Murcia (Madrid: Hiperión, 1981) 242-243.

${ }^{20}$ FERnández de LeBorans, 1.57.

2) SAgirario RoILAN, Fxperiencia y expresión de la angustia en la noche mística (lovaina: 198.3) 62 . 
La interpretación que del poema hace Allison Peers, no alcanza esta dimensión cósmica, permaneciendo, sin embargo en el plano ascético: «In the language of the poem of the Dark Night, he has left the House of Sense, and is plunged into that Night of Purgation» 22 [En el lenguaje del poema de la Noche oscura, ha dejado la casa de los sentidos, para precipitarse en la Noche de Purgación l, purgación que nos transmite un sentido de ejercicio ascético, de práctica espiritual sin expresar si se alcanza o no la unión del alma con Dios, y sin asomarse siquiera a la sima ontológica y metafísica del concepto de la noche.

La «casa», como imagen poética, refleja su espíritu, la parte humana de éste, después del dramático proceso de despojamiento que hemos explicado, tanto como los sentidos, y no tanto las sensaciones o las percepciones, sino la aprehensión del mundo exterior. La repetición de «estando ya mi casa sosegada" alude a la dificultad inherente de, siendo humano, acallar los sentidos que le atan a la vida terrenal. estado logrado sólamente después de un largo y continuo proceso de ascesis, y que es condición indispensable, aunque no suficiente, para la consecución de la mística unión con Dios.

Por su parte, «la escala» y «en celada», así como «la almena», provienen del lenguaje guerrero y caballeresco. en un reino donde su mismo nombre. Castilla, evoca con fuerza ese pasado militar medieval, y cuyas practicas - como bien experimento el propio Juan de la Cruz, que fue encarcelado por sus enemigos del Carmelo- seguían teniendo plena vigencia, y esto casi un siglo después de haber acabado la llamada Reconquista, la expulsión-conversión de los no católicos, y de haber acabado lo que después se denominó la Edad Media propiamente dicha.

«La escala» es un instrumento, una herramienta que, en movimiento vertical ascendente o descendente, sirve para huir o escapar de la prisión a que involuntariamente, el hombre se ve reducido, que impide el goce de la libertad, en este caso el goce del Bien Supremo, que es el amado; Dios. La «celada» es, en la terminología medieval caballeresca. la pieza de la armadura que cubría la cabeza, ocultándola y protegiéndola, pero también es la emboscada o trampa que con engaño pone al que en ella cae en poder del enemigo, quedando a su merced. En este sentido es como la utiliza Juan de la Cueva: «Pusimos diez mil moros en celada y el ganado dejamos salir fuera» ${ }^{23}$.

En cuanto a la imagen de la almena y del aire, según ha estudiado Dámaso Alonso, Garcilaso, en la Égloga segunda, la utiliza como escenario de fondo a la escena amorosa entre Silvanio y Celia, de ahí fue puesta a lo divino por

2 Al.lison E. PEFRs. Studies of the Spanish Mustics (London: SPCK, 1951$) 200$

23 Jian dr: la CuEva, Las siéte infarmés de Lara. citado por Ruano 74. 
Sebastián de Córdoba, de donde Juan de la Cruz debió tomarla, divinizándo$\mathrm{la}^{24}$. La imagen de la «luz» se puede considerar, en contraposición a la imagen de la «noche», y siguiéndola en importancia, como el segundo símbolo más profundo de la creación de Juan de la Cruz. Como señala Leborans, «La mayor parte de las connotaciones inherentes a la unidad léxico-semántica luz en la obra de nuestros místicos, son de origen bíblico, especialmente cuando su término de referencia es todo aquel contenido relativo a la trascendencia divina, al ámbito sobrenatural» 25 .

A lo largo de la Edad Media, la luz había simbolizado la luz divina, que emanaba de Dios. Ésto se refleja no solo en la literatura, sino en todas las demás artes, que, como es sabido, a lo largo de todo este periodo están supeditadas al estamento religioso. Pero donde alcanzan expresión metafísica, llegando a influir incluso en la estructura de los templos, es en las catedrales góticas. En ellas, los amplios parámetros - libres ahora de carga estructural debido al desarrollo técnico de la arquitectura en la Baja Edad Mediase cubren con magnificas vidrieras, cuya iconografía simboliza pasajes de las Sagradas Escrituras, pero cuya esencia, la luz que las atraviesa sin alterar su materia ni su forma, simboliza la luz de Dios que atraviesa el alma iluminándola y llenándola de gracia pero sin turbarla, aunque en algunas ocasiones, ya con nuestros escritores místicos se convirtiera en un fuego abrasador.

En el poema de la Noche, la luz es, además, guía que lleva e ilumina, en medio de la oscuridad más profunda, al alma hacia el amado, y para dejarse guiar tiene que volverse a salir primero para luego penetrar en su corazón, que es donde la luz «ardía», y es e el centro de la afectividad del místico. La luz nos sitúa, además, inmediatamente, en la vía iluminativa, que es la vía en la cual, habiendo alcanzado un alto grado de perfección el alma, y sin haber llegado a la unión propiamente dicha, ésta se ilumina con la visión de Dios, y se hace consciente de los gozos que le esperan si persevera por el camino de la perfección espiritual hasta alcanzar a Dios.

En lo que se refiere a la expresión erotizante o amorosa de esta poesía, no obsta para que el tema no sea amoroso sino místico: Jorge Guillén dice al hablar del tema, que porque el origen de su poesía sea una experiencia mística, no quiere decir que la expresión deba de ser mística, así «No se puede imaginar una mayor distancia entre la experiencia y su expresión" ${ }^{26}$.

24 AlONSO, 55-56.

25 Fernández do Leborans, 224.

26 JORGE GuJlifn, «San Juan de la Cruz o lo inefable místico», Lenguaje y poesía (Madrid: Alianza, 1969) 83. 
Su erotismo es, pues, inherente a su expresión, es parte de ella, y ayuda a una conexión emocional directa entre el lector lego y el poeta, y tiene su origen bíblico en el Cantar de los Cantares, con el tema salomónico de la búsqueda y encuentro del amado, «maravillosamente elusivo», como lo califica García Lorca ${ }^{27}$.

Desde la vertiente de tradición musulmana, Asín Palacios lo explica así: «EI origen de este alambicado y sutil recurso literario, que se sirve de términos eróticos profanos para analizar y expresar al vivo las espirituales efusiones del amor divino, es cristiano y neoplatónico al mismo tiempo, pues arranca del Cantar de los Cantares, entendido simbólicamente por los exegetas de la época patrística, a la luz de los teoremas alejandrinos que conciben a Dios como el prototipo y la fuente de belleza absoluta» ${ }^{2 *}$.

Podemos concluir con la doctora Asún, que le fueron necesarias imágenes del amor humano para dar idea de las que el sintió cono divinas ${ }^{29}$, y estas se hallaban en la tradición bíblica y neoplatónica que se presta admirablemente a la expresión de lo inexpresable: la experiencia de amor divino.

\section{Obras Consultadas}

AlBORG, Juan L. Historia de la literatura española. I. Madrid: Gredos, 1967.

Alonso, Dámaso. La poesía de San Juan de la Cruz (Desde esta ladera). 4. ${ }^{\mathrm{a}}$ ed. Madrid: Aguilar, 1966.

Aranguren, José Luis. San Juan de la Cruz. Madrid: Júcar, 1973.

Asín Palacios, Miguel. Huellas del lslam. Madrid: Espasa, 1941.

- «Un precursor hispanomusulmán de San Juan de la Cruz». Al-Ándalus. I. (1933) 126-128.

- El Islam cristianizado. Estudio del sufismo a través de las obras de Abenarabi de Murcia. Madrid: Hiperión, 1981.

Asún. Raquel. Edición, introducción y notas. San Juan de la Cruz. Poesía completa y comentarios en prosa. Barcelona: Planeta. 1986.

Ballestero. Manuel. Juan de la Cruz: de la angustia al olvido. Barcelona: Península, 1977.

- Introducción, selección y anotaciones. San Juan de la Cruz: Poesía y prosa. Madrid: Alianza, 1984.

2 FRANC ISCO GaR(ta-LoRCA, De Fray Luis a san Iuan (Madrid: Castalia. 1972) 191.

28 Asin Pal.acios. 246.

29 Raglea. Asin. San Juan de la Cruz. Poesía completa y comentarios en prosa (Barcelona: Planeta, 1986) XXI. 
Baruzi, Jean. Saint Jean de la Croix et le problème de l'expérience mystique. Paris: Alcan, 1924.

BleIBERG, Germán (dir.). Diccionario de historia de España. 3 vols. Madrid: Revista de Occidente, 1968.

CePeda, Pacho, et al. Antropología de San Juan de la Cruz. Ávila: Diputación Provincial, 1988.

Cernuda, Luis. Poesía y literatura. Barcelona: Seix Barral, 1960.

DORRE, Blanca Maria. El simbolismo de la luz en la poesía de Juan Ramón Jiménez. Michigan: Ann Arbor, 1987.

Fernández de Leborans, María Jesús. Introducción de Antonio Prieto. Luz y oscuridad en la mística española. Madrid: Cupsa, 1978.

García-LorCa, Francisco. De Fray Luis a San Juan. Madrid: Castalia, 1972.

Gómez-Ávila, María-Tulia. Thesis Saint John of the Cross. Saint Louis University Press, 1985.

Gulllén, Jorge. «San Juan de la Cruz o lo inefable místico.» Lenguaje y poesia: algunos casos españoles. Madrid: Alianza, 1969.

Jones, Royston Oscar. «Siglo de Oro: prosa y poesía (siglos XVI y XVII). Historia de la literatura española. Barcelona: Ariel, 1982.

LAmiquiz, Vidal. El sistema verhal del español. Málaga: Ágora, 1982.

López-Barai.t, Luce. Huellas del Islam en la literatura española. De Juan Ruiz a Juan Goytisolo. Madrid: Hiperion, 1985.

Mancho Duque, María Jesús. El símbolo de la noche en San Juan de la Cruz: Estudio lexicosemántico. Salamanca: Universidad de Salamanca, 1982.

Márquez. Vil.lanueva, Francisco. Espiritualidad y literatura en el siglo XVI. Madrid: Alfaguara, 1968.

Menéndez. Pelayo, Marcelino. La mística española. Madrid: Afrodisio Aguado, 1956.

Morales Borrero, Manuel. Geometría mística del alma en la literatura española del Siglo de Oro. Madrid: FUE, 1975.

Orozco, Emilio. Poesía y mística. Introducción a la lírica de San Iuan de la Cruz. Madrid: Guadarrama, 1959.

Pacho, Eulogio. Vértice de la poesia y de la mústica. El Cántico Espiritual de San Juan de la Cruz. Burgos: Monte Carmelo, 1983.

Priks, Allison Edgard. Studies of the Spanish Mystics. 2 vols. 2nd. ed. London: SPCK, 1951.

Pinilios, José Luis. La mente humana. Madrid: Salvat, 1969.

Rolı́Án, Sagrario. Experiencia y expresiön de la angustia en la noche mistica. Lovaina, 198.3.

Ruano, Argimiro. San Juan de la Cruz clásico. Teoría de lo inefable. Río Piedras: Edil, 1971.

Ruzz, Fernando. Mistico y maestro. Madrid: EDE, 1986. 
Sainz Rodríguez, Pedro. Introducción a la Historia de La Literatura Mística en España. Madrid: Espasa Calpe, 1984.

Salinas, Pedro. La realidad y el poeta. Barcelona: Ariel, 1976.

SERIS, Homero. Guía de nuevos temas de literatura española. Madrid: Castalia, 1973.

VALENTE, José Ángel. La piedra y el centro. Madrid: Taurus, 1983.

VERGOTE, André. Interprétation du langage religieux. Paris: Seuil, 1974.

YNDURÁn, Francisco. Mistica y poesía en San Juan de la Cruz. Madrid: Revista de Literatura. II, 1952.

Zambrano, María. «San Juan de la Cruz. De la Noche Oscura a la más clara mística», Andalucía, sueño y verdad. Granada: Biblioteca de Cultura Andaluza, 1984. 